\title{
Canonical correlation analysis between collaborative networks and innovation: A case study in information technology companies in province of Tehran, Iran
}

\author{
Ahmad Jafar Nejad ${ }^{a}$, Jafar Bagheri Nejad ${ }^{b}$ and Sepehr Sepehri ${ }^{{ }^{*}}$
}

${ }^{a}$ Professor, University of Tehran, Tehran, Iran

${ }^{b}$ Department of Industrial Engineering, Alzahra University, Tehran, Iran

${ }^{c}$ M.S Candidate of MBA, University of Economic Sciences, Tehran, Iran

\section{H R O N I C L E}

\section{Article history:}

Received January 30, 2013

Received in revised format

20 May 2013

Accepted May 282013

Available online

June 32013

\section{Keywords:}

Regional Innovation System

Collaboration Networks

Innovation

Canonical Correlation Analysis

\section{A B S T R A C T}

The increase competitions as well as technological advancements have created motivation among business owners to look for more innovative ideas from outside their organizations. Many enterprises collaborate with other organizations to empower themselves through innovative ideas. These kinds of collaborations can be observed as a concept called Regional Innovation System. These collaborations include inter-firm collaborations, research organizations, intermediary institutions and governmental agencies. The primary objective of this paper is to evaluate relationships between Collaborative Networks and Innovation in information technology business units located in province of Tehran, Iran. The research method utilized for the present study is descriptive-correlation. To evaluate the relationships between independent and dependent variables, canonical correlation analysis (CCA) is used. The results confirm the previous findings regarding the relationship between Collaborative Networks and Innovation. Among various dimensions of Collaboration, Collaboration with governmental agencies had a very small impact on the relationship between collaboration networks and innovation. In addition, the results show that in addition to affecting product innovation and process innovation, collaboration networks also affected management innovation.

\section{Introduction}

Many experts in the area of management consider "collaboration" as future business culture and strategy. In today's competitive business environment where most firms are encountered with increasing demand for resources of innovation and technology, current competitive advantage and internal resources of firms are considered insufficient for improvement. Collaboration then is a useful tool for developing competitive advantages, filling the existing gap between current and desired capabilities of firms in complex environment of global competition and sudden changes.

*Corresponding author. Tel +989131271542

E-mail addresses: sepehri_sepehr@yahoo.com (S. Sepehri) 
Reviewing the literature of innovation indicates that during the past two decades, there have been tremendous changes on fundamental of innovation, which is the results of growing use of collaboration networks (Hagedoorn, 2002). Most business owners depend on external innovation resources like ideas, resources, and individuals who come in and out to organizations (Chesbrough, 2003). Nowadays most managers and experts believe that collaboration is a crucial resource for creating successful innovations for firms.

A lot of studies have been conducted on the effects of collaboration on product innovation and process innovation. These studies have confirmed positive relationship between collaboration with organizations and companies' innovations. Hence there are scattered and few studies about evaluating relationship between Collaboration Network and Management Innovation. Exploring this relationship in the framework of regional innovation systems, especially in developing countries has received little attention. Many active organizations in information technology have almost the same sensitivity for product innovation, process innovation and management innovation. Therefore, they can be considered as a good example for exploring the relationship between collaboration networks and these kinds of innovations. Regarding these situations, software companies in Tehran, are selected for this research.

The aim of this study is to evaluate the relationship between Collaboration Network and Innovation in firms through the canonical correlation analysis on the data obtained from the information technology in Tehran province. This study is an attempt to answer the following questions: Is there any meaningful relationship between Collaboration Network and Innovation? If there is any meaningful relationship, which one of the criteria of Collaboration Network and Innovation has the most and which one has the least impact on creating the meaningful relationship? In fact, this article increases the insight of managers about the effects of Collaboration to lead their efforts to successful Innovation.

\section{Literature review}

\subsection{Innovation}

Manu (1992) categorized Innovation as product innovation, process innovation, and management innovation. Product innovation includes new products or services developed for satisfying customer demands (Manu, 1992). Process innovation is new factors implemented in manufacture's and service's processes in firms such as raw materials, task descriptions, working mechanism, and information flow (Utterback \& Abernathy, 1975). Management innovation can be detected in literature of management under various terms. Recent researchers implement innovation management (Mol \& Birkinshaw, 2009), managerial innovation (Damanpour \& Aravind, 2011), or organizational innovation (Battisti \& Stoneman, 2010). The definitions of administrative, organizational, and management innovations overlap considerably ( Damanpour \& Aravind, 2011).

The literature on management innovation is scarce and scattered (Mol \& Birkinshaw, 2009). Apart from some early contributions (Damanpour et al., 1989), the importance of management innovation as a distinct innovation type has only emerged in the last decade. The OECD (2005) recognition of management innovation as separate from product, process, and marketing innovations by calling it as Organizational Innovation, partly triggered this change in direction. Recent studies have expanded the concept of Organizational Innovation (Armbruster et al., 2008; Hamel, 2006; Hamel \& Breen, 2007). Management innovation is the invention and implementation of a management practice, process, structure or technique that is new and is intended to further organizational goals (Birkinshaw et al., 2008). A new performance measurement, strategic planning or Total Quality Management is the example of this kind of innovation. 
The measures of product innovation, process innovation, and management innovation are depicted in Table 1 (Jiménez-Jimenez et al., 2008; Manu, 1992).

\section{Table 1}

Measures of Innovations

Measures

Product innovation

1.Number of new products/services introduced

2.Pioneer disposition to introduce new products/services

3.Efforts on innovation in terms of hours/person, teams and training involved in innovation

Process innovation

1.Number of changes in the process introduced

2.Pioneer disposition to introduce new process

3.Quick response to the introduction of competitors' new Processes

Management innovation

1.Novelty of the management systems

2.Search of new management systems

3.Pioneer disposition to introduce new management Systems

\subsection{Collaboration Networks}

Networking can be used as a complementary factor in the conditions where companies need networking to reach economic of scale, integrating skills, technologies and different competencies (Mancinelli \& Mazzanti, 2009). SMEs' requirement for collaborating as complementing factor for internal resources are dominated in academic discussions (Fukugawa, 2006) but business units have a few external relationships in process of innovation (Kaminski \& de Oliveira, 2008). Researchers believe that firms' position in collaboration network can influence on their abilities for gaining effective resources.

Firms are in the context, which consists of other companies and organizations, interacting with each other. Regarding innovation systems, it can be said that firms do their innovative activities in regional innovation systems and develop their collaboration networks in this framework. Doloreux (2004) mentioned four elements in regional innovation systems. These elements are categorized as firms, institutions, information platform, and innovative policies. Technological innovation system is the set of networks, which includes actors and institutions which interact in a specific technology and produce, diffuse, and exploit new technology or product (Markard \& Truffer, 2008). Main structural elements of technological innovation system are actors and institutions. Actors consist of different firms, universities, research organizations, capital adventures, consultants, associations, and customers with various competencies, resources and strategies. Institutions not only are the facilitators for actors' decisions and activities but also constrain them and include standards, laws, values, collective expectations, and cultures (Markard \& Truffer, 2008).

Firm's ability for connecting and jumping in different innovation systems as competitive advantage determines the success of firms. Having relationships with more extensive networks, not only provides various resources of knowledge as inputs for firms, but also stabilizes their business activities (Doloreux \& Parto, 2004). Zeng et al. (2010) categorized collaboration networks into four dimensions: government agencies, inter-firm, intermediary institutions, and research organizations.

\subsubsection{Collaboration with research organizations}

Research institutions, universities, collages, and technical institutions are innovation partners for firms. Informal collaboration with research organizations includes knowledge, skills, and technology transfers. On the other hand, formal collaboration consist of formal research activities such as: R\&D 
alliance, R\&D outsourcing, training innovative employees, and providing graduate employees with sufficient knowledge and skills (Liefner et al., 2006). Belderbos et al. ( 2004) believed that cooperating with research institutions is an effective way for gaining the innovations required to enter new markets.

Normally collaboration with research organizations and graduate institutions provides important resources for new knowledge in developing countries (Liefner et al., 2006). Razak and Saad (2007) found out that universities were responsible for providing graduate students with knowledge and skills and they are the places for fostering new industries, products and services. However lake of relationship between companies and universities, limits the external stimulus for innovation (Kaminski \& de Oliveira, 2008).

\subsubsection{Collaboration with government agencies}

The internationalization of economics and politics has forced local governments to develop new context-appropriate strategies characterized by a greater degree (higher level) of interaction with nongovernmental key actors and with the business world in particular (Yáñez et al., 2008). In general, collaboration with external actors, business in particular, is an essential governance task (Mossberger $\&$ Stoker, 2001). The trend of networking makes new challenges for governance in developing countries. The requirements of governance and management considerations challenge preexisting government systems (Keast \& Hampson, 2007). Therefore, the broader public policy governance literature has advocated a network governance mode based on a social or communal organizing principle.

In general, improving service provision for firms is an essential governance task. Collaboration with government agencies refers to government-sponsored agreements-publicly funded collaboration stimulated by government research and development programs, which provide public subsidies and allows indirectly the firm either to open up a new research project or to expand an existing one (Matt $\&$ Wolff, 2004). Although this collaborative pattern is stable, it is less persistent in the long run in case of success (Matt \& Wolff, 2004).

\subsubsection{Inter-firm collaboration}

In inter-firm collaboration, innovation partners are customers, suppliers, manufactures, service providers and competitors. There are a lot of researches indicating that collaboration between customers and suppliers could improve innovation (Cooke, 2001; Diez, 2000; Doloreux, 2004). Networking is most likely exploited by firms that have already conducted R\&D with the innovative intent to seek collaborative scale opportunities (Bergman, 2009). The attention devoted to networking reflects various real-world situations where inter-firm collaboration is the crucial key to successful performance of both the companies and the whole network (Mancinelli \& Mazzanti, 2009).

Firms pursue inter-firm collaboration in order to tap into sources of know-how located outside the boundaries of the firm, to gain fast access to new technologies or new markets, to benefit from economies of scale in joint $\mathrm{R} \& \mathrm{D}$ and/or production and to share the risks for activities that are beyond the scope or capabilities of a single firm (Fischer \& Varga, 2002).

\subsubsection{Collaboration with Intermediary institutions}

Intermediary institutions, such as technology intermediaries, financing and training institutions, venture capital organizations, technology transfer organizations and technology market play some important roles within the innovation process, which have been variously described as intermediary firms, bridges, information intermediaries and innovation intermediaries (Howells, 2006). Generally, intermediaries maintain functions in innovation, including communication, foresight and diagnostics, 
information scanning and gathering, knowledge processing and combination, evaluation of outcomes, and commercialization (Howells, 2006).

Doloreux (2004) suggested that external relationship with intermediary institutions for firms, could be the good source for new ideas for innovation and technological productivity. (Gebauer et al., 2005) showed that intermediary institutions such as technology and innovation centers were important and essential for local entrepreneurship. Therefore, there is a weak integrated relationship between firms and intermediary institutions in innovation process. In general, intermediary institutions have an important role to support firms, then collaboration with intermediary institutions can lead to more innovation for firms (Zeng et al., 2010). Based on researches which have been conducted in Japanese firms, networking is an essential tool for facilitating innovation and providing access to experts and resources (Fukugawa, 2006). Nieto and Santamaría (2007) explored the relationship between product innovation and collaboration networks and found out that there was a positive relationship between collaboration with suppliers and novelty of product innovation. Firms' collaborative behaviors had a relationship with their innovation outcomes based on this research; more collaboration with different kinds of firms and organizations increases the probability of innovation, which is commercially successful. Tomlison (2010) reported that collaboration throughout supply chain could increase the probability of innovation in the firms. The measures of collaboration networks (research organizations, government agencies, inter-firm, and intermediary institutions) are shown in table 2 .

\section{Table 2}

Measures of Collaboration

\begin{tabular}{|c|c|}
\hline Measures & Authors \\
\hline $\begin{array}{l}\text { Collaboration with research organizations } \\
\text { 1.Collaboration with Universities } \\
\text { 2.Collaboration with research institutions } \\
\text { 3.Collaboration with colleges/ technical institutes }\end{array}$ & $\begin{array}{l}\text { (Diez, 2000; Doloreux, 2004; Nieto \& Santamaría, 2007; Zeng et } \\
\text { al., 2010) }\end{array}$ \\
\hline $\begin{array}{l}\text { Collaboration with government agencies } \\
\text { 1.Collaboration with innovation services department } \\
\text { 2.Collaboration with information services department } \\
\text { 3.Collaboration with supervision services department }\end{array}$ & $\begin{array}{l}\text { (Biggs \& Shah, 2006; Diez, 2000; Doloreux, 2004; Hewitt- } \\
\text { Dundas, 2006) }\end{array}$ \\
\hline $\begin{array}{l}\text { Inter-firm collaboration } \\
\text { 1.Collaboration with customers and client } \\
\text { 2.Collaboration with suppliers } \\
\text { 3. Collaboration with competitors/rivals }\end{array}$ & $\begin{array}{l}\text { (Doloreux, 2004; Nieto \& Santamaría, 2007; Tether \& Tajar, } \\
\text { 2008) }\end{array}$ \\
\hline $\begin{array}{l}\text { Intermediary institutions } \\
\text { 1.Collaboration with technology intermediaries } \\
\text { 2.Collaboration with technology market } \\
\text { 3.Collaboration with industrial associations } \\
\text { 4.Collaboration with venture capital organizations }\end{array}$ & (Diez, 2000; Pekkarinen \& Harmaakorpi, 2006) \\
\hline
\end{tabular}

This proposed model is composed of two types of variables: collaboration networks and innovations as shown in Fig. 1. Therefore, the question is: Is there any meaningful relationship between collaboration networks (collaboration with research organizations, government agencies, inter-firm, and intermediary institutions) and innovation (product innovation, process innovation, and management innovation) in firms? The following questions will be also investigated:

1. Is there any correlation between Collaboration Network criteria and innovation criteria?

2. In a set of Collaboration network criteria, which one has the most and which one has the least impact on creating a meaningful relationship between Collaboration Network and Innovations?

3. In a set of Innovation criteria, which one has the most and which one has the least impact on creating a meaningful relationship between Collaboration Network and Innovations? 


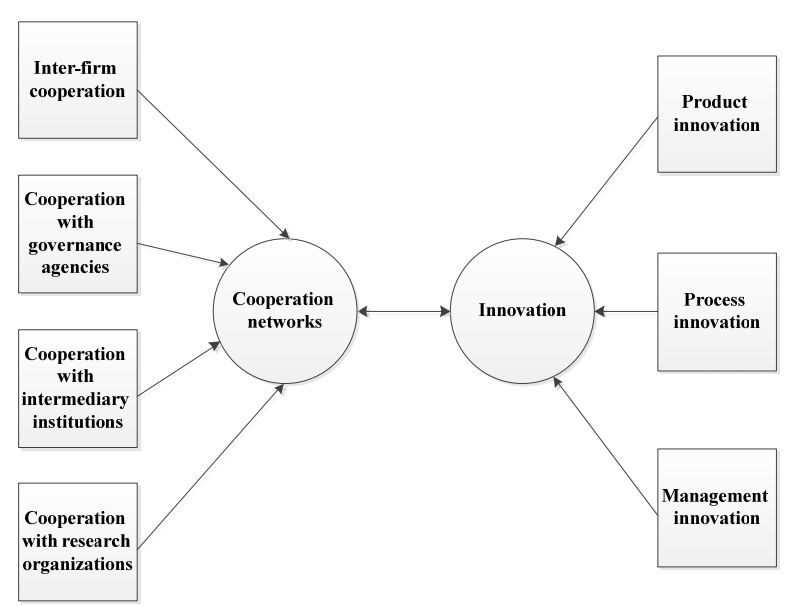

Fig. 1. Research proposed model

\section{Research methodology}

The data of this research is gathered from companies, which focus their activities in software developing and information technology industries in Tehran Province. Tehran province by including 1102 companies has about $70 \%$ of all software developing and information technology companies which are in Iran. 500 electronic questionnaires were distributed. 323 questionnaires were received by authors that showed $65 \%$ rate of return for questionnaires. Because of having missed data, 11 questionnaires were eliminated. Fig. 2 shows the characteristics of the sample.

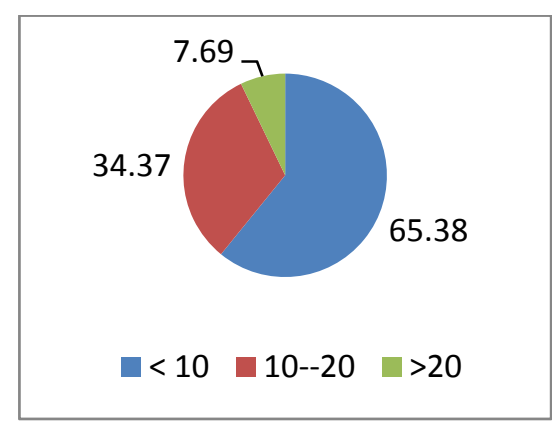

Years of Job experience

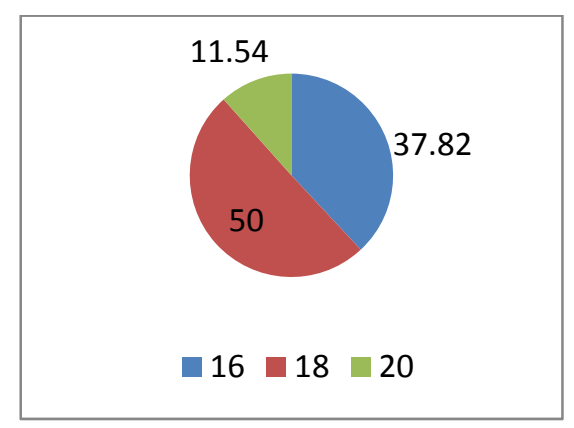

Educational background

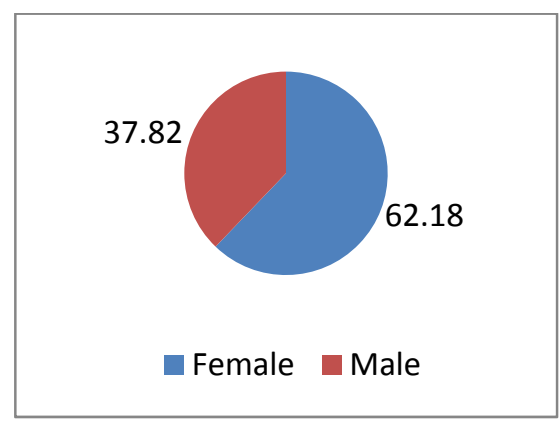

Gender

Fig. 2. Personal characteristics of participants

Research method is used for this article is descriptive-correlation. To assess the relations between the sets of collaboration network and Innovation, canonical correlation analysis (CCA) was used. Statistica 7 was used to perform CCA method. For this investigation, first available literature, relationships between criteria in Collaboration Network and Innovation and literature review were studied. The questionnaire had 13 questions for collaboration network in 4 dimensions and 9 questions for innovation in 3 dimensions. Items of constructs are assessed with a 5-Likert scale ranging from 1 to 5 with the following equivalences, "1: very low"; "2: low"; " 3 : neutral"; "4: high"; "5: very high".

Table 3

Correlation coefficient between Collaboration Network' criteria and Innovation's criteria

\begin{tabular}{lccc}
\hline Correlation coefficient & Product Innovation & Process Innovation & Management Innovation \\
\hline Inter- firm collaboration & 0.592 & 0.591 & 0.453 \\
Governance agencies & 0.377 & 0.284 & 0.353 \\
Intermediary Institutions & 0.556 & 0.419 & 0.391 \\
Research organizations & 0.635 & 0.499 & 0.543 \\
\hline
\end{tabular}


Regarding the first sub-question, based on Table 3, a meaningful positive correlation can be seen between Collaboration network's criteria and Innovation's criteria. Several interesting relationships were detected in Table 3. For instance, "Collaboration with research organization" criterion and "Product Innovation" criterion have the strongest correlation and "Collaboration with governance agencies" and "Process innovation" has the least correlation. Also in Collaboration network's criterion, "Collaboration with research organizations" criterion has the most and "Collaboration with governance agencies" criterion on have the least correlation with "Product Innovation". Furthermore, "Inter-firm collaboration" criterion has the most and "Collaboration with governance agencies" criterion has the least correlation with "Process innovation" criterion. In addition, "Collaboration with research organizations" criterion has the most and "Collaboration with governance agencies" criterion has the least correlation with "Management innovation" criterion.

\section{Table 4}

Canonical correlation analysis summary

\begin{tabular}{lll}
\hline $\mathrm{N}=312$ & Collaboration Network & Innovation \\
\hline Number of variables & 4 & 3 \\
Variance extracted & $80.39 \%$ & $100.00 \%$ \\
Total redundancy & $34.01 \%$ & $41.20 \%$ \\
\hline Variables: & & \\
1 & Inter- firm collaboration & Product Innovation \\
2 & Governance agencies & Process Innovation \\
3 & Intermediary Institutions & Management Innovation \\
4 & Research organizations & \\
\hline
\end{tabular}

Table 4 shows Extracted variance of the data by CCA. The extracted variance for Collaboration Network and Innovation shows that $80.39 \%$ of internal variations in Collaboration Networks are covered by canonical roots and also $100 \%$ of internal variations in Innovations are covered by canonical roots. The figures are very high and, therefore, support CCA utilization. The level of significance of a canonical correlation generally considered to be the minimum acceptable level for interpretation is the 0.05 level, which (along with the 0.01 level) has become the generally accepted level for considering a correlation coefficient statistically significant (Joseph F. Hair, Black, Babin, \& Anderson, 2010). In this study, Canonical function 1 and 2 have been found statistically significant ( $p$ $<.05$ ). Considering redundancy index and extracted variance (Table 5), only function 1 will be interpreted .In addition, multivariate tests like Wilk's lambda is also performed (Table 5). Consequently, just the first variable pair may be interpreted.

\section{Table 5}

Canonical correlation analysis

\begin{tabular}{llllll}
\hline Canonical function & Canonical correlation & Canonical R2 & F statistics & probability & Wilks' Lambda \\
\hline 1 & 0.745657 & 0.556004 & 138.1155 & 0.000000 & 0.400648 \\
2 & 0.275152 & 0.075709 & 15.5125 & 0.016642 & 0.902369 \\
3 & 0.154007 & 0.023718 & 3.6246 & 0.163295 & 0.976282 \\
\hline
\end{tabular}

To answer the research question, we refer to the Table 5. The magnitude of the relationships between the Collaboration Networks and the Innovations sets is determined by the canonical correlation (Rc) and the eigenvalue $(\lambda \mathrm{i})$. The Rc of the first canonical function is 0.7457 and the eigenvalue is 0.556 meaning that the Collaboration Networks as a whole account for more than 55 per cent of the underlying variance in the Innovations. This can be interpreted as an evidence of a strong relationship between the Collaboration Networks and Innovation in the companies. To carry out interpretation of the CCA, we analyzed the magnitude of the redundancy Total (Table 5). This index shows that the average ability of the set of Collaboration networks to explain the variation of the Innovations is almost 41 per cent. These results can be interpreted as a measure of the ability of the Collaboration Network to exert an influence on the set of Innovations. In other words, these findings can be understood as a measure of the capability of the companies to achieve better innovations by 
cooperating with other organizations. Table 6 represents canonical results of the dependent and independent sets for two functions.

Table 6

Canonical results

\begin{tabular}{lcccc}
\hline Innovations & Canonical variable 1 & \multicolumn{2}{c}{ Canonical variable 2 } \\
& loading & cross loading & loading & -0.013 \\
cross loading
\end{tabular}

Regarding the second and the third sub questions, canonical cross loading was used for evaluating the importance of every criterion in meaningful canonical variable. In general, the researcher faces the choice of interpretation of the functions using canonical weights (standardized coefficients), canonical loadings (structure correlations) or canonical cross loadings. Given a choice, it is suggested that cross loadings are superior to loadings, which are in turn superior to weights (Hair et al., 2010). According to Table 6, all variables in both sets have a high canonical cross loading in creating a canonical variable in their sets. Therefore, they are very effective in creating a meaningful relationship between Collaboration Network and Innovation. Among the Collaboration Network's criteria, "Research organizations" and "Inter- firm" have the highest impact and "Governance agencies" has the lowest impact in creating this relationship. Also among Innovation criteria, "Product Innovation" has the highest effect and "Management Innovation" has the lowest effect in creating this relationship. In addition, based on the high level of canonical cross loading in both sets, it can be concluded that Collaboration Network's criteria have a positive and strong impact on Innovation criteria. Furthermore, for CCA validity, sensitivity analysis was used on independent variables. For this validation, one of Collaboration Network's variables was eliminated every time and CCA was utilized. Outputs showed no impression change in construct coefficient of variables.

\section{Conclusion}

This study was an attempt to investigate the relationship between Collaboration Network and Innovation by using CCA in software developing and information technology Companies. Understanding relationships between these sets will give companies a wide perspective to manage their relation with other organizations. For this investigation, first available literature, relationships between Collaboration Network and Innovation and literature review were studied. Then data was gathered by electronic questionnaires through software developing and information technology companies and at the end analyzed output by utilizing CCA. Research findings confirmed that the set of Collaboration Network is strongly related to the innovation set and all criteria, except collaboration with governance agencies, in both sets have a high canonical cross loading in creating a canonical variable in their sets. Therefore, they are very effective in creating a meaningful relationship between collaboration network and innovation. So, a balanced approach in networking makes it possible to maximize the correlation between Collaboration network's criteria and innovation's criteria and, therefore, obtain an optimal profit. Therefore, Companies should not focus their relation on one or two kind of collaboration such customers or suppliers, but should also pay attention to every actor in technological innovation system, considering the collaboration network as a whole. This result confirms studies of (Diez, 2000; Liefner et al., 2006; Miotti \& Sachwald, 2003; Verhees \& Meulenberg, 2004). Also according to the results we can claim that in collaboration network`s 
criteria, "Research organizations" and "Inter- firm", and in Innovation's criteria, "Product Innovation" and "Process Innovation" have the highest impact on creating a meaningful relationship. (Belderbos et al., 2004) highlighted the collaboration with Research Organizations as the most effective way to achieve innovations intended to open new markets and segments. Usually, collaboration with public research institutions and higher education institutions is an important source of new knowledge for companies in developing countries (Liefner et al., 2006). On the Other hand, collaboration with governance agencies has the lowest effect on creating a meaningful relationship. We can also claim that in developing countries the rolls of governance agencies are not well defined, therefore they do not have very effective role in innovation process.

\section{References}

Armbruster, H., Bikfalvi, A., Kinkel, S., \& Lay, G. (2008). Organizational innovation: The challenge of measuring non-technical innovation in large-scale surveys. Technovation, 28(10), 644-657.

Battisti, G., \& Stoneman, P. (2010). How innovative are UK firms? evidence from the fourth UK community innovation survey on synergies between technological and organizational innovations. British Journal of Management, 21(1), 187-206.

Belderbos, R., Carree, M., \& Lokshin, B. (2004). Cooperative R\&D and firm performance. Research Policy, 33(10), 1477-1492.

Bergman, E. M. (2009). Embedding network analysis in spatial studies of innovation. The Annals of Regional Science, 43(3), 559-565.

Biggs, T., \& Shah, M. K. (2006). African SMES, networks, and manufacturing performance. Journal of Banking and Finance, 3043-3066.

Birkinshaw, J., Hamel, G., \& Mol, M. J. (2008). Management innovation. Academy of Management Review, 33(4), 825-845.

Chesbrough, H. W. (2003). Open innovation: The new imperative for creating and profiting from technology: Harvard Business Press.

Cooke, P. (2001). Regional innovation systems, clusters, and the knowledge economy. Industrial and corporate change, 10(4), 945-974.

Damanpour, F., \& Aravind, D. (2011). Managerial innovation: Conceptions, processes, and antecedents. Management and Organization Review, 8(2), 423-454.

Damanpour, F., Szabat, K. A., \& Evan, W. M. (1989). The relationship between types of innovation and organizational performance. Journal of Management Studies, 26(6), 587-602.

Diez, J. R. (2000). Innovative networks in manufacturing: some empirical evidence from the metropolitan area of Barcelona. Technovation, 20(3), 139-150. doi: 10.1016/s0166-4972(99)00112-1

Doloreux, D. (2004). Regional networks of small and medium sized enterprises:evidence from the metropolitan area of Ottawa in Canada. European Planning Studies, 173-189.

Doloreux, D., \& Parto, S. (2004). Regional innovation systems: a critical synthesis. United Nations University, Institute for New Technologies, Discussion Paper Series, 17.

Fischer, M. M., \& Varga, A. (2002). Technological innovation and interfirm collaboration: an exploratory analysis using survey data from manufacturing firms in the metropolitan region of Vienna. International Journal of Technology Management, 24(7), 724-742.

Fukugawa, N. (2006). Determining factors in innovation of small firm networks: A case of cross industry groups in Japan. Small Business Economics, 27(2), 181-193.

Gebauer, H., Fleisch, E., \& Friedli, T. (2005). Overcoming the service paradox in manufacturing companies. European Management Journal, 23(1), 14-26.

Hagedoorn, J. (2002). Inter-firm R\&D partnerships: an overview of major trends and patterns since 1960. Research Policy, 31(4), 477-492.

Hamel, G. (2006). The why, what, and how of management innovation. Harvard Business Review, 84(2), 72.

Hamel, G., \& Breen, B. (2007). The future of management: Harvard Business School Press.

Hewitt-Dundas, N. (2006). Resource and capability constraints to innovation in small and large plants. Small Business Economics, 26(3), 257-277. 
Howells, J. (2006). Intermediation and the role of intermediaries in innovation. Research Policy, 35(5), 715-728.

Jiménez-Jimenez, D., Valle, R. S., \& Hernandez-Espallardo, M. (2008). Fostering innovation: the role of market orientation and organizational learning. European Journal of Innovation Management, 11(3), 389-412.

Joseph F. Hair, J., Black, W. C., Babin, B. J., \& Anderson, R. E. (2010). Multivariate Data Analysis (7 ed.): Prentice Hall.

Kaminski, P. C., \& de Oliveira, A. C., Lopes,T.M. (2008). Knowledge transfer in product development processes:a case study in small and medium enterprises (SMEs) of the metal-mechanic sector from Sao Paulo, Brazil. Technovation, 29-36.

Keast, R., \& Hampson, K. (2007). Building constructive innovation networks: Role of relationship management. Journal of Construction Engineering and Management, 133(5), 364-373.

Liefner, I., Hennemann, S., \& Xin, L. (2006). Collaboration in the innovation process in developing countries:empirical evidence from Zhongguancun,Beijing. Environment and Planning, 111-113-.

Mancinelli, S., \& Mazzanti, M. (2009). Innovation, networking and complementarity: Evidence on SME performances for a local economic system in North-Eastern Italy. The Annals of Regional Science, 43(3), 567-597.

Manu, F. A. (1992). Innovation orientation, environment and performance: A comparison of US and European markets. Journal of International Business Studies, 333-359.

Markard, J., \& Truffer, B. (2008). Actor-oriented analysis of innovation systems: exploring micro-meso level linkages in the case of stationary fuel cells. Technology Analysis \& Strategic Management, 20(4), 443-464. doi: 10.1080/09537320802141429

Matt, M., \& Wolff, S. (2004). Incentives, coordination and learning in government-sponsored vs. spontaneous inter-firm research collaboration. International Journal of Technology Management, 27(8), 694-711.

Miotti, L., \& Sachwald, F. (2003). Co-operative R\&D: why and with whom?: An integrated framework of analysis. Research Policy, 32(8), 1481-1499. doi: 10.1016/s0048-7333(02)00159-2

Mol, M. J., \& Birkinshaw, J. (2009). The sources of management innovation: When firms introduce new management practices. Journal of Business Research, 62(12), 1269-1280.

Mossberger, K., \& Stoker, G. (2001). The evolution of urban regime theory the challenge of conceptualization. Urban Affairs Review, 36(6), 810-835.

Nieto, M. J., \& Santamaría, L. (2007). The importance of diverse collaborative networks for the novelty of product innovation. Technovation, 367-377.

Pekkarinen, S., \& Harmaakorpi, V. (2006). Building regional innovation networks: The definition of an age business core process in a regional innovation system. Regional Studies, 40(4), 401-413.

Razak, A. A., \& Saad, M. (2007). The role of universities in the evolution of the Triple Helix culture of innovation network: The case of Malaysia. International Journal of Technology Management \& Sustainable Development, 6(3), 211-225.

Tether, B. S., \& Tajar, A. (2008). The organisational-collaboration mode of innovation and its prominence amongst European service firms. Research Policy, 37(4), 720-739. doi: 10.1016/j.respol.2008.01.005

Tomlinson, P. R. (2010). Co-operative ties and innovation: Some new evidence for UK manufacturing. Research Policy, 39(6), 762-775. doi: 10.1016/j.respol.2010.02.010

Utterback, J. M., \& Abernathy, W. J. (1975). A dynamic model of process and product innovation. Omega, 3(6), 639-656.

Verhees, F. J. H. M., \& Meulenberg, M. T. G. (2004). Market orientation, innovativeness, product innovation, and performance in small firms. Journal of Small Business Management, 42(2), 134-154.

Yáñez, C. J. N., Magnier, A., \& Ramírez, M. A. (2008). Local Governance as Government-Business Collaboration in Western Democracies: Analysing Local and Intergovernmental Effects by MultiLevel Comparison. International Journal of Urban and Regional Research, 32(3), 531-547.

Zeng, S. X., Xie, X. M., \& Tam, C. M. (2010). Relationship between collaboration networks and innovation performance of SMEs. Technovation, 181-194. 